Martina Absinta, MD

Govind Nair, $\mathrm{PhD}$

Pascal Sati, PhD

Irene C.M. Cortese, MD

Massimo Filippi, MD

Daniel S. Reich, MD,

$\mathrm{PhD}$

Correspondence to

Dr. Reich:

reichds@ninds.nih.gov
Supplemental data at Neurology.org/nn

\section{Direct MRI detection of impending plaque development in multiple sclerosis OPEN}

\section{ABSTRACT}

Objectives: To detect and localize MRI signal changes prior to the parenchymal contrast enhancement that classically defines the radiologic onset of the developing white matter lesion in multiple sclerosis (MS).

Methods: We reviewed 308 high-resolution ( $\leq 1 \mathrm{~mm}^{3}$ voxels) MRI scans at 3T and 7T in 29 patients with active MS. The presence of pre-parenchymal enhancement abnormalities before the appearance of parenchymal enhancement was evaluated in all available scans.

Results: Pre-enhancement signal changes were noted in 26 of 162 enhancing lesions (16\%) as linear enhancement of the central vein and/or perivenular hyperintense signal on T2 fluidattenuated inversion recovery or T2* images. They occur up to 2 months before focal enhancement within the parenchyma in $10 \%$ of cases.

Conclusions: In some lesions, the abrupt opening of the blood-brain barrier, detected by contrast enhancement on MRI, can have directly visible antecedent MRI changes centered on the central vein. We propose that these findings might be the basis for prior reports of subtle pre-parenchymal enhancement changes in quantitative MRI indices. In line with the venulocentric model of lesion development, our findings are consistent with the centrality of early perivenular events in lesion formation in vivo. Neurol Neuroimmunol Neuroinflamm 2015;2:e145; doi: 10.1212/ NXI.0000000000000145

\section{GLOSSARY}

BBB $=$ blood-brain barrier; EDSS $=$ Expanded Disability Status Scale; FLAIR = fluid-attenuated inversion recovery; MPRAGE = magnetization-prepared rapid gradient-echo; $\mathbf{M S}=$ multiple sclerosis.

In multiple sclerosis (MS), 2 distinct etiologic models have been proposed to explain the events leading to blood-brain barrier (BBB) disruption and perivenular inflammatory demyelination ${ }^{1}$ : (1) the "outside-in" hypothesis, in which an autoimmune process leads to infiltration of myelinautoreactive T cells and monocytes around the developing lesion's central vein; and (2) the "inside-out" hypothesis, in which primary oligodendrocyte degeneration drives a cascade of inflammatory changes within the parenchyma, including nonperivenular clusters of activated microglia ${ }^{2,3}$ and subtle diffuse tissue injury.

Although the events that lead to development of each focal lesion might be distinct from those that trigger the disease as a whole, the great interest in this topic has led to the recognition of subtle in vivo MRI changes that precede the dramatic radiologic appearance of newly forming MS lesions: leakage of IV contrast material into the parenchyma. To this end, lower magnetic transfer ratio, ${ }^{4,5}$ higher $^{6}$ or reduced ${ }^{7}$ mean diffusivity, higher choline peak, ${ }^{8}$ higher perfusion, ${ }^{9}$ and altered magnetic susceptibility ${ }^{10}$ have been detected weeks to months before parenchymal contrast enhancement, confirming that pathologic processes in the so-called normal-appearing white matter can contribute to the lesion onset. However, the pathologic origin of these signal

From the Division of Neuroimmunology and Neurovirology (M.A., G.N., P.S., I.C.M.C., D.S.R.), National Institute of Neurological Disorders and Stroke, NIH, Bethesda, MD; and Neuroimaging Research Unit (M.A., M.F.), Institute of Experimental Neurology, Division of Neuroscience, San Raffaele Scientific Institute, Vita-Salute San Raffaele University, Milan, Italy.

Funding information and disclosures are provided at the end of the article. Go to Neurology.org/nn for full disclosure forms. The Article Processing Charge was paid by the authors.

This is an open access article distributed under the terms of the Creative Commons Attribution-NonCommercial-NoDerivatives License 4.0 (CC BY-NC-ND), which permits downloading and sharing the work provided it is properly cited. The work cannot be changed in any way or used commercially. 
changes, especially their localization relative to features of the developing lesion and its central vein, are not fully understood.

In this study, we reviewed 308 MRI scans in 29 patients with MS to address 2 main questions: (1) Can we directly visualize preenhancement signal changes with contemporary high-resolution MRI? (2) Are such changes diffuse within the region of impending demyelination or focused around the central vein?

METHODS We reviewed 308 MRI scans (acquired between 2010 and 2014) in 29 patients with active MS (16 women) selected from our database for the presence of supratentorial discrete enhancing lesions and at least one previous scan acquired at 3T or 7T. All patients were enrolled under an institutional review board-approved natural history protocol. The $3 \mathrm{~T}$ scans included pre- and/or postcontrast T2 fluid-attenuated inversion recovery (FLAIR) and postcontrast T1-weighted magnetization-prepared rapid gradient-echo (MPRAGE) sequences; when available, T2* weighted sequences were also evaluated. The $7 \mathrm{~T}$ scans included precontrast T2-FLAIR or T2* and postcontrast T1-MPRAGE sequences. All images had a voxel resolution $\leq 1 \mathrm{~mm}^{3}$ (table e-1 at Neurology.org/nn). Standard-dose gadolinium-based contrast agent was injected, and postcontrast T1-weighted images were acquired $\geq 5$ minutes afterward. Of 308 scans, $62(20 \%)$ were acquired at $7 \mathrm{~T}$.

Disease course was relapsing-remitting in 24 patients and progressive in 5. Median Expanded Disability Status Scale (EDSS) score was 1.5 (range $0-7.5$ ), mean disease duration was 8.2 years (SD 7.3), and mean age was 40 years (SD 11). Twelve patients were untreated; 17 were on various disease-modifying treatments.

A neuroradiologist and a neurologist with extensive experience in MS imaging evaluated the presence of pre-parenchymal enhancement abnormalities (any abnormal finding in the vicinity of the future lesion) before the appearance of parenchymal enhancement in all available scans. Images were reviewed on a clinical workstation (Carestream Vue) where data could be rigidly registered and reformatted in different planes.

Student $t$ test and Fisher exact test were used to assess the main demographic (age, sex), clinical (disease duration, EDSS, disease phenotype, treatment status), and imaging differences between patients with and without at least one lesion with preparenchymal enhancement findings.

RESULTS The mean number of scans per patient was 10 (median 9); the mean follow-up was 1.7 years (SD 0.8 , range $0.3-3.1$ years). Of 308 scans, $87(28 \%)$ showed enhancing lesions. There were 162 enhancing lesions with prior scans that were evaluated for pre-parenchymal enhancement signal abnormalities. The mean number of enhancing lesions per patient was 5 (median 2, SD 7, range 1-29). The most recent prior scan was within 2 months for 121 of 162 enhancing lesions (75\%); for the remaining 41 lesions, the most recent prior scan was within 6 months.

In 26 of 162 enhancing lesions (16\%), preparenchymal enhancement MRI abnormalities were noted and classified according to the temporal relationship to parenchymal gadolinium enhancement. Up to
2 months before, we noticed (1) linear enhancement of the central vein without parenchymal hyperintensity on FLAIR images ( 5 lesions in 5 patients, range 8-31 days before, figure 1A); or (2) hyperintense signal on T2-FLAIR that was absent in prior scans (6 cases, range 14-42 days before, figure $1 \mathrm{~B}$ ) and that colocalized with the developing lesion's central vein (T2*-weighted images available in 3 cases). One case presented both features 15 days before lesion enhancement (figure 1C). Considering that only 121 enhancing lesions had a prior scan acquired within 2 months, the prevalence of these findings was $10 \%$.

In the remaining 14 enhancing lesions, small areas of long-lasting signal abnormality (figure 2) were seen months to years before enhancement (range 2.8-30 months). On T2*-weighted sequences (available in 6 cases), the finding appeared to span a section of what later became the lesion's central vein (figure 2). On postcontrast T2-FLAIR, the mean diameter was 2.4 $\mathrm{mm}$ (SD 0.8) and stable over time. In 8, hypointense signal on T1-weighted images was also discerned (mean diameter $2.2 \mathrm{~mm}, \mathrm{SD} 0.63$ ).

Patients with pre-parenchymal enhancement findings had a higher number of enhancing lesions than those without (mean lesion number 8 vs $2, p=$ $0.01)$ and were younger $(p=0.03)$. No other demographic and clinical differences were found between groups.

DISCUSSION Some novel observations about MS lesion development in vivo derive from the present analysis. In approximately $15 \%$ of new active lesions, parenchymal enhancement has directly visible antecedent MRI changes that, in cases where the $\mathrm{T} 2{ }^{*}$ weighted sequence was available for investigation, are centered on the central vein. In contrast to previous assessments, ${ }^{4-6,8-10}$ the abnormalities seen here are not inferred statistically on the basis of group-level analysis but directly visualized at the patient/lesion level, providing the opportunity to better study associated morphologic features. In particular, we took advantage of optimized $\mathrm{T} 2 *$-weighted sequences at $3 \mathrm{~T}$ and $7 \mathrm{~T}$ to confirm the primary role of the central vein in early stages of lesion development, specifically before BBB disruption.

In line with the venulocentric model of lesion development, we discerned the presence of linear enhancement along the central vein preceding the parenchymal enhancement on postcontrast T1weighted scans by days to weeks (figure 1). Slow flow associated with leukocyte rolling and/or entrapment of contrast agent within the perivascular space without passage through the glia limitans may explain this finding. In some cases, small parenchymal signal changes on T2-FLAIR or T2*-weighted scans around the vein were detected days to weeks before 

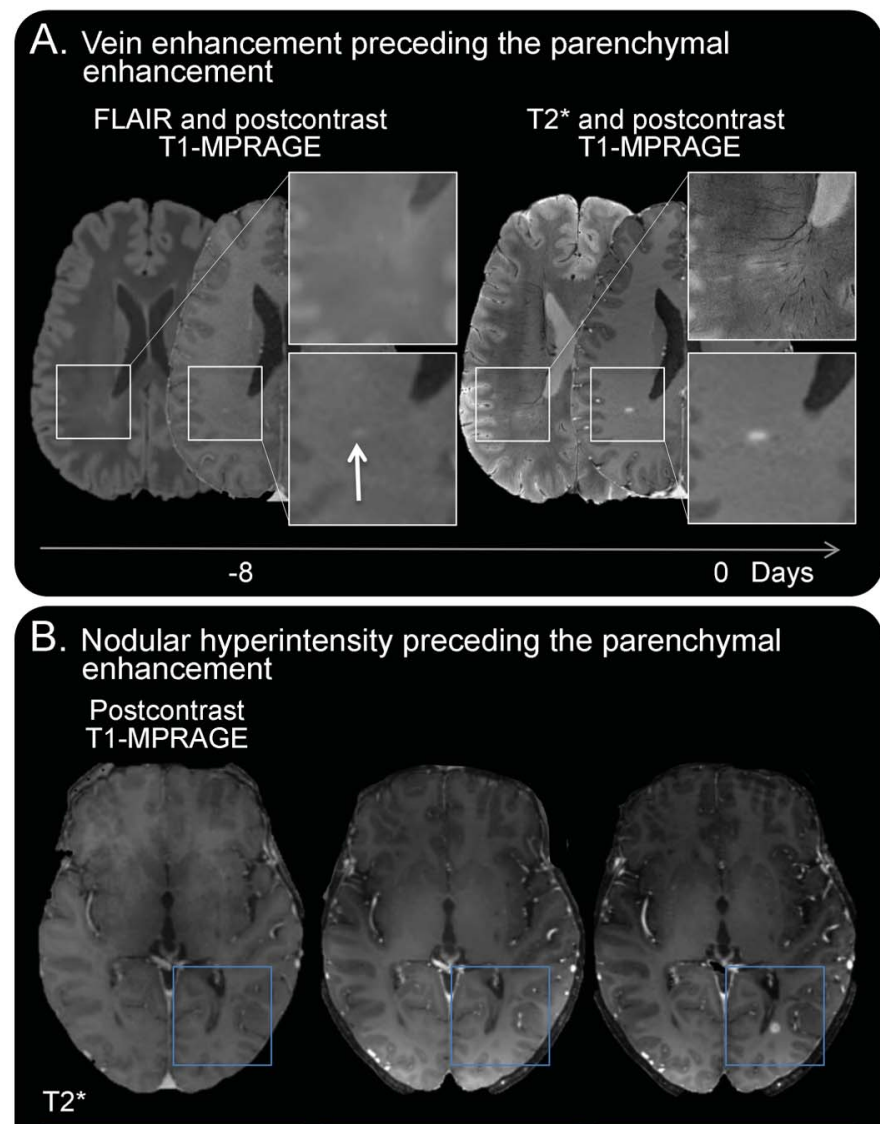

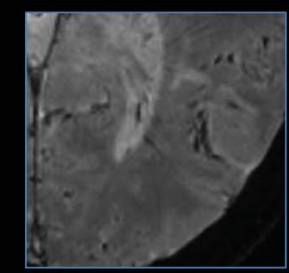

$-3$

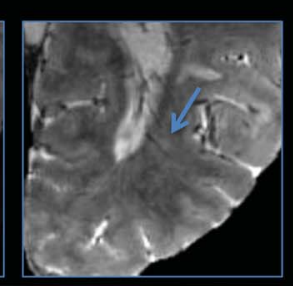

$-1.4$

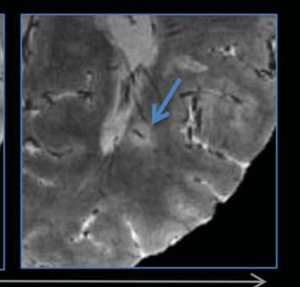

0 Months
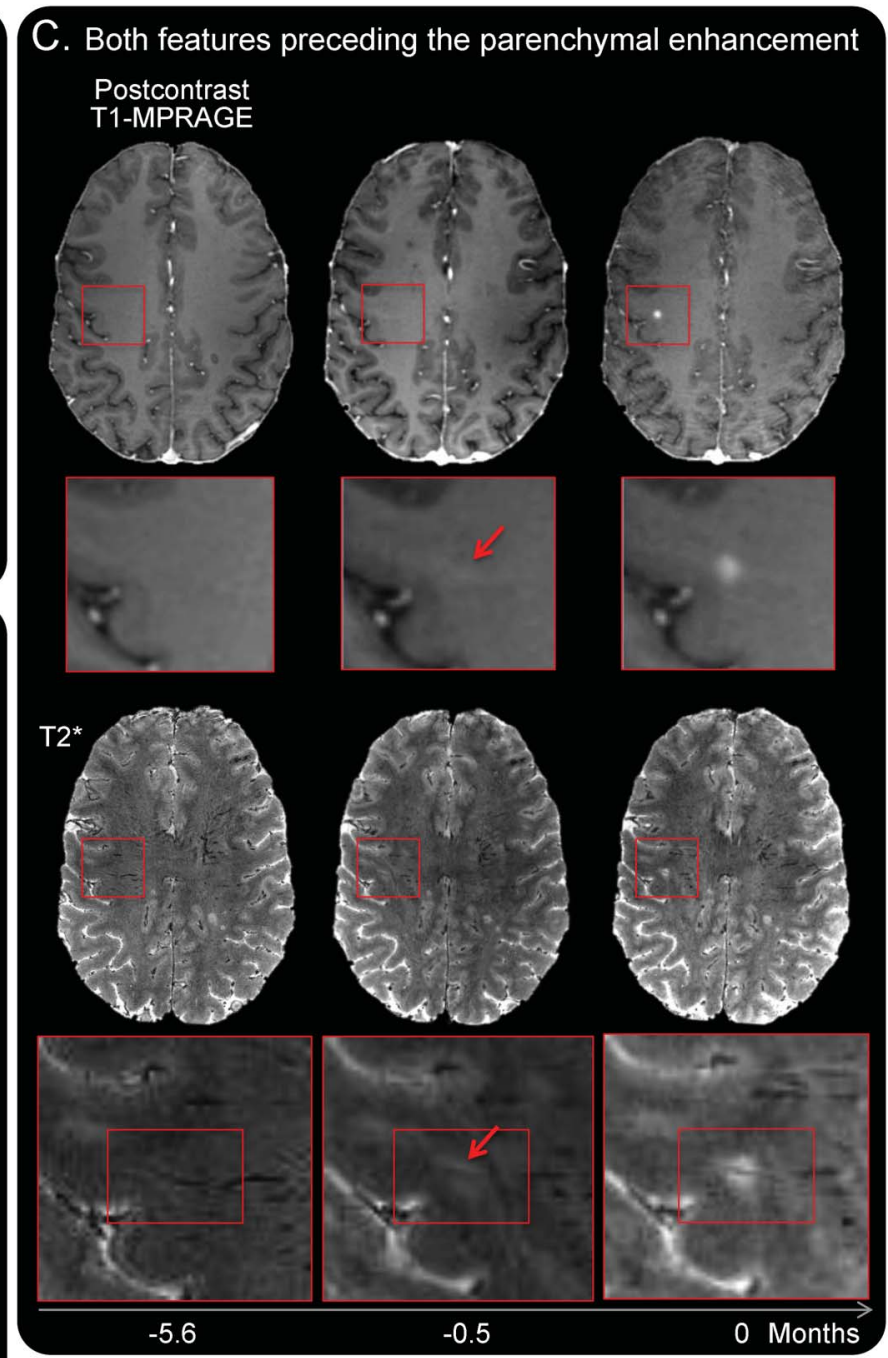

(A) Even in the absence of postcontrast 3T T2 fluid-attenuated inversion recovery (FLAIR) signal abnormality, isolated linear intravascular enhancement (arrow) is depicted on postcontrast T1 magnetization-prepared rapid gradient-echo (MPRAGE) images 8 days before the development of an enhancing lesion in the right parietal white matter (37-year-old man with relapsing-remitting multiple sclerosis [MS], Expanded Disability Status Scale [EDSS] score 0, and disease duration 0.8 years). (B) On 7T T2*-weighted images, subtle hyperintense signal around a prominent central vein (arrow) is discerned 44 days before, but not 3 months before, parenchymal lesion enhancement (38-year-old woman with relapsing-remitting MS, EDSS score 1.5, and disease duration 7.6 years). (C) Linear intravascular enhancement (arrow) on postcontrast 7T T1-MPRAGE and hyperintensity around the central vein (diameter $3 \mathrm{~mm}$, arrow) on 7T T2*-weighted images were detected 14 days before the appearance of parenchymal enhancement in the right frontal white matter. No corresponding signal abnormalities were detected in postcontrast 7T T1-MPRAGE and T2*-weighted images acquired 5.6 months before (49-year-old woman with progressive MS, EDSS score 5.5, and disease duration 21 years).

parenchymal enhancement (figure 1), which might reflect hypercellularity (possibly reactive astrocytes, activated microglia, and some lymphocytes), ${ }^{11}$ minimal parenchymal edema, axonal dysfunction, ${ }^{12}$ and/or initial demyelination in the presence of a still partially intact BBB.

In other cases, newly forming lesions arise from longer-lasting (months to years) areas of alreadyabnormal MRI signal (figure 2). This may indeed suggest the presence of preexisting or aborted demyelination centered on the same vein that does not meet the traditional MRI-based definition of an MS lesion (generally $\geq 3 \mathrm{~mm}$ diameter). These data raise the intriguing possibility that perivenular areas already subjected to previous inflammation may have increased susceptibility to subsequent demyelination.

Taken together, our data suggest that early perivenular processes, probably related largely to cellular infiltration but relatively limited in scope, occur frequently in MS but are not necessarily visible with gadolinium. It is possible that the relatively low frequency of pre-enhancement findings reported here may relate to selective permeability of the BBB in some lesions, which might be overcome by the use of higher doses of gadolinium or perhaps an entirely different contrast agent. Further increases in spatial 
Figure 2 Long-lasting pre-parenchymal enhancement MRI findings
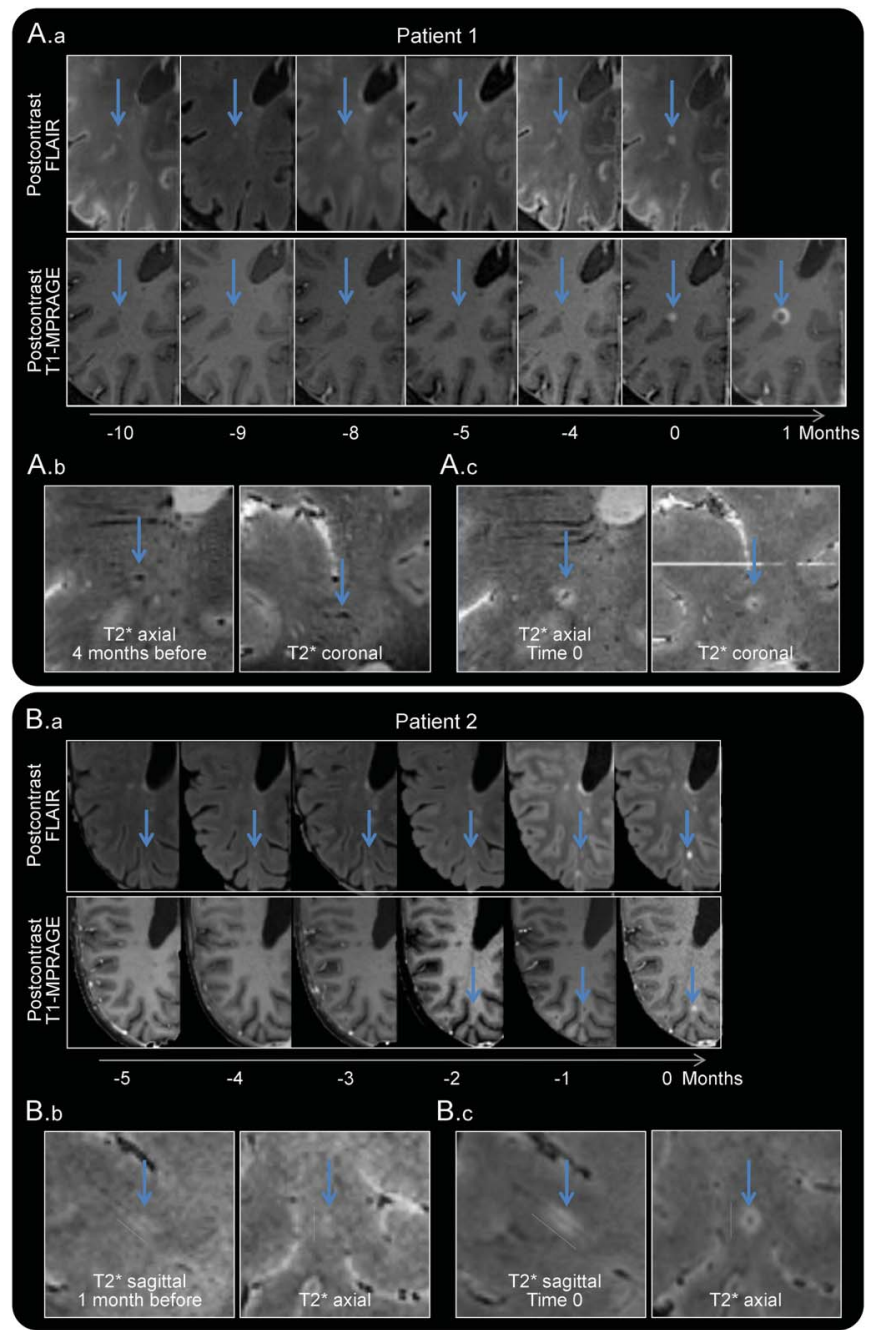

Patient 1 (A.a-A.c). A new right juxtacortical parietal lesion develops at time 0 (same patient as in figure 1C). In A.a, a small area, hyperintense on T2 fluid-attenuated inversion recovery (FLAIR) and hypointense on postcontrast T1 magnetization-prepared rapid gradient-echo (MPRAGE) images (diameter 1.7 and $1.4 \mathrm{~mm}$, respectively), is clearly visible several months before parenchymal enhancement and remains stable in size. At time 0 , the lesion enhances centrifugally from the central vein; at month 1 , the enhancement pattern is centripetal. (A.b, A.c) On 7T T2*-weighted axial and coronal magnified views, subtle bright signal around the prominent central vein is seen 4 months before parenchymal lesion enhancement. Patient 2 (B.a-B.c). A new right parietal white matter lesion in a 42-year-old woman with relapsingremitting multiple sclerosis (Expanded Disability Status Scale score 3, disease duration 3 years). In B.a, a long-lasting hyperintense area on 3T T2-FLAIR (diameter $3.1 \mathrm{~mm}$ ) is detected in all previous available scans but not in all the postcontrast T1-MPRAGE images. On 3T T2*weighted images, its elongated structure around the central vein (B.b, axial and sagittal magnified views) is seen a month before parenchymal enhancement (B.c, time 0).

resolution and frequent scanning of patients developing active lesions might allow detection of additional short-term perivenular changes. Our retrospective study design, which marshaled data from an existing natural history protocol, kept us from evaluating these possibilities. The same design limitations prevented us from directly comparing our results to prior group-level analyses using quantitative MRI methods. ${ }^{4-6,8-10}$ Despite these limitations, our data suggest that parenchymal gadolinium leakage in lesions heralds the onset of processes directly related to demyelination. Such processes may include massive recruitment of blood-derived macrophages, which have been shown to be essential for clearance of myelin debris and initiation of tissue repair. ${ }^{13-15}$

\section{AUTHOR CONTRIBUTIONS}

Dr. Absinta and Dr. Reich: study concept and design. Dr. Absinta, Dr. Sati, Dr. Nair, and Dr. Cortese: acquisition of data. Dr. Absinta and Dr. Reich: analysis and interpretation. Dr. Absinta, Dr. Reich, Dr. Sati, Dr. Nair, Dr. Cortese, and Dr. Filippi: critical revision of the manuscript for important intellectual content. Dr. Reich: study supervision.

\section{ACKNOWLEDGMENT}

The authors thank the study participants, the Neuroimmunology Clinic for recruiting and evaluating the patients and for coordinating the scans, and the NIH Functional MRI Facility.

\section{STUDY FUNDING}

The Intramural Research Program of the National Institute of Neurological Disorders and Stroke supported this study.

\section{DISCLOSURES}

M. Absinta reports no disclosures. G. Nair received intramural funding from the NIH. P. Sati and I. Cortese report no disclosures. M. Filippi is on the scientific advisory board for Teva; received travel funding and/or speaker honoraria from Biogen, Excemed, Novartis, and Teva; is editor-in-chief of Journal of Neurology; is an editorial board member for AJNR, BMC Musculosketal Disorders, Clinical Neurology and Neurosurgery, Erciyes Medical Journal, Journal of Alzheimer's Disease, Journal of Neuroimaging, Journal of Neurovirology, Lancet Neurology, Magnetic Resonance Imaging, Multiple Sclerosis, and Neurological Sciences; has consulted for Biogen, Excemed, Novartis, and Teva; is on the speakers' bureau for Biogen, Excemed, Novartis, and Teva; and received research support from Biogen-Idec, Novartis, Teva, Italian Ministry of Health, Fondazione Italiana Sclerosis Multipa, The Gossweiler Foundation, Alzheimer's Drug Discovery Foundation, and ARiSLA. D. Reich received research support from Vertex, National Institute of Neurological Disorders and Stroke, and Myelin Repair Foundation. Go to Neurology.org/nn for full disclosure forms.

Received May 14, 2015. Accepted in final form June 24, 2015.

\section{REFERENCES}

1. Tallantyre EC, Brookes MJ, Dixon JE, Morgan PS, Evangelou N, Morris PG. Demonstrating the perivascular distribution of MS lesions in vivo with 7-Tesla MRI. Neurology 2008;70:2076-2078.

2. van Noort JM, van den Elsen PJ, van Horssen J, Geurts JJ, van der Valk P, Amor S. Preactive multiple sclerosis lesions offer novel clues for neuroprotective therapeutic strategies. CNS Neurol Disord Drug Targets 2011;10:68-81.

3. Singh S, Metz I, Amor S, van der Valk P, Stadelmann C, Bruck W. Microglial nodules in early multiple sclerosis white matter are associated with degenerating axons. Acta Neuropathol 2013;125:595-608.

4. Filippi M, Rocca MA, Martino G, Horsfield MA, Comi G. Magnetization transfer changes in the normal appearing white matter precede the appearance of enhancing lesions in patients with multiple sclerosis. Ann Neurol 1998;43:809-814.

5. Goodkin DE, Rooney WD, Sloan R, et al. A serial study of new MS lesions and the white matter from which they arise. Neurology 1998;51:1689-1697.

6. Werring DJ, Brassat D, Droogan AG, et al. The pathogenesis of lesions and normal-appearing white matter 
changes in multiple sclerosis: a serial diffusion MRI study. Brain 2000;123:1667-1676.

7. Eisele P, Szabo K, Griebe M, et al. Reduced diffusion in a subset of acute MS lesions: a serial multiparametric MRI study. AJNR Am J Neuroradiol 2012;33:1369-1373.

8. Tartaglia MC, Narayanan S, De Stefano N, et al. Choline is increased in pre-lesional normal appearing white matter in multiple sclerosis. J Neurol 2002;249:1382-1390.

9. Wuerfel J, Bellmann-Strobl J, Brunecker P, et al. Changes in cerebral perfusion precede plaque formation in multiple sclerosis: a longitudinal perfusion MRI study. Brain 2004; 127:111-119.

10. Wiggermann V, Hernandez Torres E, Vavasour IM, et al. Magnetic resonance frequency shifts during acute MS lesion formation. Neurology 2013;81:211-218.
11. Maggi P, Macri SM, Gaitan MI, et al. The formation of inflammatory demyelinated lesions in cerebral white matter. Ann Neurol 2014;76:594-608.

12. Nikic I, Merkler D, Sorbara C, et al. A reversible form of axon damage in experimental autoimmune encephalomyelitis and multiple sclerosis. Nat Med 2011;17:495-499.

13. Miron VE, Boyd A, Zhao JW, et al. M2 microglia and macrophages drive oligodendrocyte differentiation during CNS remyelination. Nat Neurosci 2013;16:1211-1218.

14. Bogie JF, Stinissen P, Hendriks JJ. Macrophage subsets and microglia in multiple sclerosis. Acta Neuropathol 2014;128:191-213.

15. Cherry JD, Olschowka JA, O'Banion MK. Neuroinflammation and M2 microglia: the good, the bad, and the inflamed. J Neuroinflammation 2014;11:98. 


\section{Neurology \\ Neuroimmunology \& Neuroinflammation}

\section{Direct MRI detection of impending plaque development in multiple sclerosis Martina Absinta, Govind Nair, Pascal Sati, et al. Neurol Neuroimmunol Neuroinflamm 2015;2; DOI 10.1212/NXI.0000000000000145}

This information is current as of September 3, 2015

\section{Updated Information \& Services \\ Supplementary Material}

References

Citations

Subspecialty Collections

Permissions \& Licensing

Reprints including high resolution figures, can be found at: http://nn.neurology.org/content/2/5/e145.full.html

Supplementary material can be found at: http://nn.neurology.org/content/suppl/2015/09/03/2.5.e145.DC1

This article cites 15 articles, 1 of which you can access for free at: http://nn.neurology.org/content/2/5/e145.full.html\#\#ref-list-1

This article has been cited by 2 HighWire-hosted articles: http://nn.neurology.org/content/2/5/e145.full.html\#\#otherarticles

This article, along with others on similar topics, appears in the following collection(s):

MRI

http://nn.neurology.org//cgi/collection/mri

Multiple sclerosis

http://nn.neurology.org//cgi/collection/multiple_sclerosis

Information about reproducing this article in parts (figures,tables) or in its entirety can be found online at:

http://nn.neurology.org/misc/about.xhtml\#permissions

Information about ordering reprints can be found online: http://nn.neurology.org/misc/addir.xhtml\#reprintsus

Neurol Neuroimmunol Neuroinflamm is an official journal of the American Academy of Neurology.

Published since April 2014, it is an open-access, online-only, continuous publication journal. Copyright $\odot$ 2015 American Academy of Neurology. All rights reserved. Online ISSN: 2332-7812.

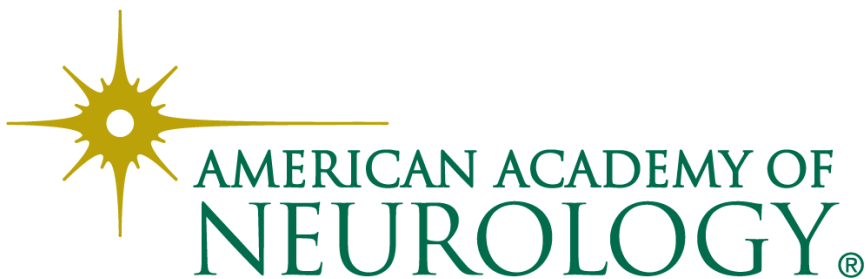

